\title{
Using nowcast model currents to explore transport of non-indigenous jellyfish into the Gulf of Mexico
}

\author{
Donald R. Johnson ${ }^{1, *}$, Harriet M. Perry ${ }^{1}$, William M. Graham ${ }^{2}$ \\ ${ }^{1}$ Center for Fisheries Research and Development, Gulf Coast Research Laboratory, The University of Southern Mississippi, \\ Ocean Springs, Mississippi 39564, USA \\ ${ }^{2}$ Dauphin Island Sea Laboratory, 101 Bienville Boulevard, Dauphin Island, Alabama 36528, USA
}

\begin{abstract}
In the spring of 2000, millions of the non-endemic jellyfish Phyllorhiza punctata were found in coastal regions of the Mississippi Bight in the northern Gulf of Mexico. The aggregations were large enough to seriously impact local fisheries by clogging shrimp nets and damaging gear. More importantly perhaps, the impact on plankton biomass and hence on fishery resources were potentially large, since $P$. punctata is a voracious filter feeder. In this study, we examine a hypothesis for their sudden appearance which involves advection from the Caribbean in an intruding Loop Current and subsequent flux onto the Mississippi Shelf through eddy-shedding processes which interact with the continental shelf/slope. Surface current data were obtained from an archived finite difference model of the Gulf of Mexico which used altimeter data assimilation and real wind forcing covering the time of the invasion. Model and satellite data showed that an exchange event occurred in late April at a time appropriate for the invasion. The results from tracing transport pathways suggest that mass redistribution of Caribbean populations into the northern Gulf of Mexico can be accomplished via Loop Current intrusion and flux of deep basin water onto the shelf. As such, the occurrence of the invasive species P. punctata in the northern Gulf in 2000 can be explained by a natural, but not necessarily common, sequence of events. This hypothesis is discussed as a means of redistribution of a species by invasion as opposed to redistribution by diffusive spreading.
\end{abstract}

KEY WORDS: Gulf of Mexico $\cdot$ Jellyfish $\cdot$ Non-indigenous $\cdot$ Numerical model

\section{INTRODUCTION}

Bioinvasion ecology in recent years has focused on predicting the ability of species to invade new territory. Assessing predictability is complicated by a number of factors involving spread, timing, environmental compatibility and stochastic character (Carlton 1996a,b, Ruiz et al. 1997). While many successful invasions can be forecast or hindcast from known pathways, perhaps most invaders have an uncertain vector (Carlton 1996a). In such cases, populations of invaders are difficult to track geographically, which, in turn, complicates management efforts.

The sudden appearance of millions of exotic jellyfish Phyllorhiza punctata von Lendenfeld, 1884 (family Mastigiidae) (Fig. 1a), in the Mississippi Bight (Fig. 1b) during summer 2000 posed an interesting set of problems in the study of biological invasions. Since the Mastigiidae radiated in the Indo-Pacific, there is little doubt about its invasiveness in the Atlantic basin and elsewhere outside the Indo-Pacific (Graham et al. 2003a and references therein). However, invasions by jellyfish like P. punctata in the northern Gulf of Mexico (GOM) are complicated by the bipartite life-history of the Scyphozoa. The invasive jellyfish or medusa stage represents only the sexually reproductive pelagic phase of these animals; complete establishment of a population requires that the benthic scyphistoma (polypoid) stage be present as well.

The extent, magnitude and ecological impacts of the Phyllorhiza punctata invasion in 2000 have been described by Graham et al. (2003a,b). At peak densities $>1$ ind. $\mathrm{m}^{-3}$, these medusae were voracious consumers of fish eggs and zooplankton. Extensive aggregations 

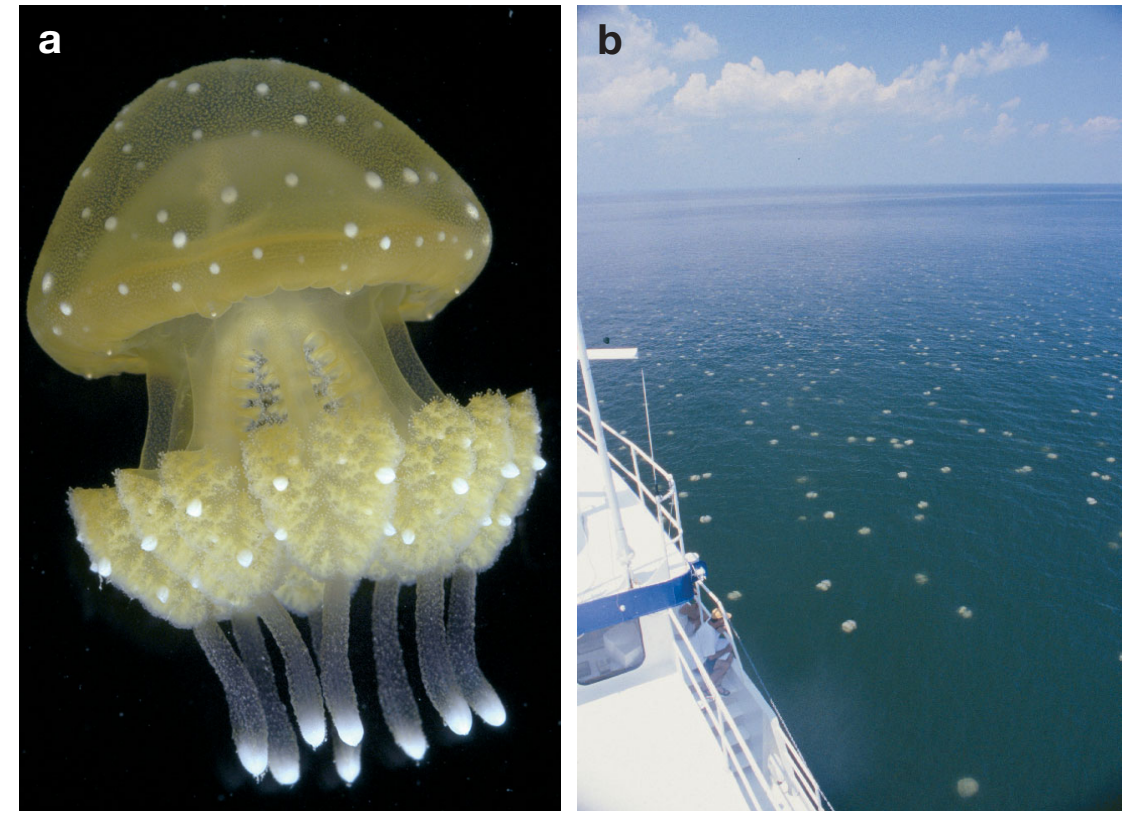

Fig. 1. (a) Phyllorhiza punctata, native to the Indo-Pacific. (b) Extensive jellyfish patch in the Mississippi Bight, June 2002

of $P$. punctata interfered with commercial shrimping along coastal Mississippi and Louisiana and could have been responsible for the unusually low shrimp harvests in 2000 (Graham et al. 2003a).

Although Graham et al. (2003a) provided the first published report of the invasion of Phyllorhiza punctata in the Mississippi Bight, there are a number of credible anecdotal reports that smaller aggregations of these medusae had been occurring for several years prior to 2000 along southern Louisiana west of the mouth of the Mississippi River, specifically in Terrebone Bay. While the potential for spreading from this source exists, we must still consider the possibility of periodic introductions of expatriate medusae from a Caribbean source with or without establishment of a population of scyphistomae in the northern GOM. The suddenness and magnitude of the 2000 event suggests that more than local spreading is involved. The purpose of this study was to investigate the possibility that the summer 2000 population of $P$. punctata medusae could have been transported from the Caribbean into the northern GOM over a relatively short period of time consistent with the biological constraints of these jellyfish (i.e. life-history and survival). This was accomplished by employing a retrospective analysis of modeled currents and satellite imagery to describe the hydrodynamic environment leading up to the first documented reports of $P$. punctata off the Mississippi/ Alabama coast in May 2000.
The northern GOM shelf circulation is forced primarily by winds, tides and freshwater discharge from several major river systems. Shelf circulation is also sporadically influenced by a complex mesoscale eddy field formed in the deep basin during intrusion of the warm, tropical Loop Current (LC). The LC, a part of the Atlantic western boundary current, intrudes into the Gulf through the Yucatan Strait, forms a loop and exits through the Florida Strait, where it eventually becomes the Gulf Stream. On a time scale of roughly 9 to 13 mo the LC expands northward into the Gulf (Elliot 1982), becomes dynamically unstable (Hurlbert \& Thompson 1980), and pinches off into an anticyclonic eddy of 200 to $300 \mathrm{~km}$ diameter. This eddy contains high salinity, warm water of Atlantic/Caribbean origin, and currents in excess of $1 \mathrm{~m} \mathrm{~s}^{-1}$.

The intrusion and eddy spin-off is a major event in the Gulf, setting off topographic Rossby waves that affect currents and density fronts along the continental slopes of the northern Gulf (Hamilton 1990, Oey 1995). The spin-off eddy propagates under the influence of the earth's rotation into the western Gulf, eventually dissipating against the Texas/Mexico coast. Along its path, smaller cyclonic eddies are formed around its perimeter which further interact with the continental slope waters of the northern Gulf, pulling streamers of water off the shelf and replacing it with deep basin water. These events, together with favorable wind stress, enhance cross-slope exchange between the shelf and the deep basin and can play a major role in structuring plankton advection routes (Johnson \& Perry 1999, Perry et al. 2003).

Circumstantial evidence at the onset of the bloom in late spring 2000, pointed to the LC as the source of the Phyllorhiza punctata bloom. At the time of their first detection, large quantities of Sargassum spp. weed and anomalously clear blue water were encroaching very close to shore. These conditions are sporadic in the northern GOM but not uncommon, and may occur when the LC intrudes northward and sheds spin-off eddies around the main anticyclone. Satellite imagery and dynamic sea surface height (http://www-ccar.colorado.edu/ leben) showed a strong northern intrusion of the LC and spin-off eddy during April and May 2000. This event was quickly adopted as the most logical explanation, and efforts to locate a source of the jellyfish in the Caribbean were initiated. 


\section{MATERIALS AND METHODS}

To develop our hypothesis of a Caribbean jellyfish origin via the intruding $\mathrm{LC}$, we required data that linked on-shelf advection to LC spin-off events during the late spring of 2000. Since such intrusions could occur anywhere within a broad area, satellite data were fundamental to our search for an appropriate intrusion pathway. During late spring, however, the thermal contrast between LC and northern GOM waters is diminished such that advanced very high resolution radiometry (AVHRR) sea surface temperature images lose their utility. Fig. 2 shows an enhanced 3 day sea surface temperature composite from 19 April 2000. Although contrasts were weak by this date, the enhancement (gamma), shows 3 warmer water streamers from the LC stretching toward the northern shelf. These filaments will be important in our analysis. Chlorophyll from optical spectra make color satellite images useful nearshore (see Fig. 3), but on the outer shelf/slope there is only marginal contrast between shelf and basin waters.

Satellite altimetry (sea surface height), on the other hand, is highly useful in the deep basin with the advantage that the altimeter is not limited by clouds. However, relatively wide satellite track separations made the nadir-pointing measurements insufficient for the resolution needed. Numerical models provide adequate resolution, but need to be phase-locked to the highly non-linear LC to produce a realistic description of its dynamics in a real-time frame. Assimilation of satellite altimetry into a numerical model provides the best use of satellite information with high resolution requirements.

Archival model results were used to trace pathways of possible jellyfish transport into and around the GOM. The numerical model is the University of Colorado version (Kantha \& Clayson 2000) of the Princeton Ocean Model (Blumberg \& Mellor 1983). It is a 3-dimensional, primitive equation, sigma-coordinate model with 21 levels in the vertical and 1/12th degree latitude/longitude horizontal resolution (about 8 to $9 \mathrm{~km}$ ). The vertical scale was stretched in order to better resolve surface and bottom boundary layers and an improved, second-order closure, mixed-layer model was incorporated (Kantha \& Clayson 1994). The model has a free surface and is run with a split-mode technique to solve the fully non-linear governing equations (Kantha \& Piacsek 1996). Time steps were $400 \mathrm{~s}$ for the baroclinic mode and $10 \mathrm{~s}$ for the barotropic mode. Surface currents from this model were averaged to daily values and archived for future exploitation.

Data assimilation of sea surface heights (converted to vertical temperature structure) during 2000 from TOPEX/Poseidon and ERS satellite altimeters was included in the model. Track-by-track continuous assimilation (4-dimensional assimilation) was done by nudging, with simple optimal interpolation. Multi-Channel Sea Surface Temperature (MCSST) 3 day composites were assimilated similarly. The model was originally run in near real-time in 2000 with observed wind stress forcing (at $6 \mathrm{~h}$ intervals) and tidal forcing, and the results were archived. It is essential to note that the assimilation of altimetry data phase locks the intrusion and spin-off eddies to real events. This is necessary, since intrusion and spin-off events are non-linear and cannot be readily modeled for real-time reconstruction without proper phasing. Validation for this operational model can be found in Kantha et al. (2006).

We applied all of the relevant information regarding the occurrence in 2000 to a hindcast with model currents in an effort to trace possible sources of the jellyfish, either by back-tracing from known endpoints or by forward-tracing from potential origins. Both forward- and back-tracing were done in a simple linear fashion. Starting at a selected location, interpolated current speed and direction were applied to determine the distance and direction of travel at $0.1 \mathrm{~d}$ time steps.

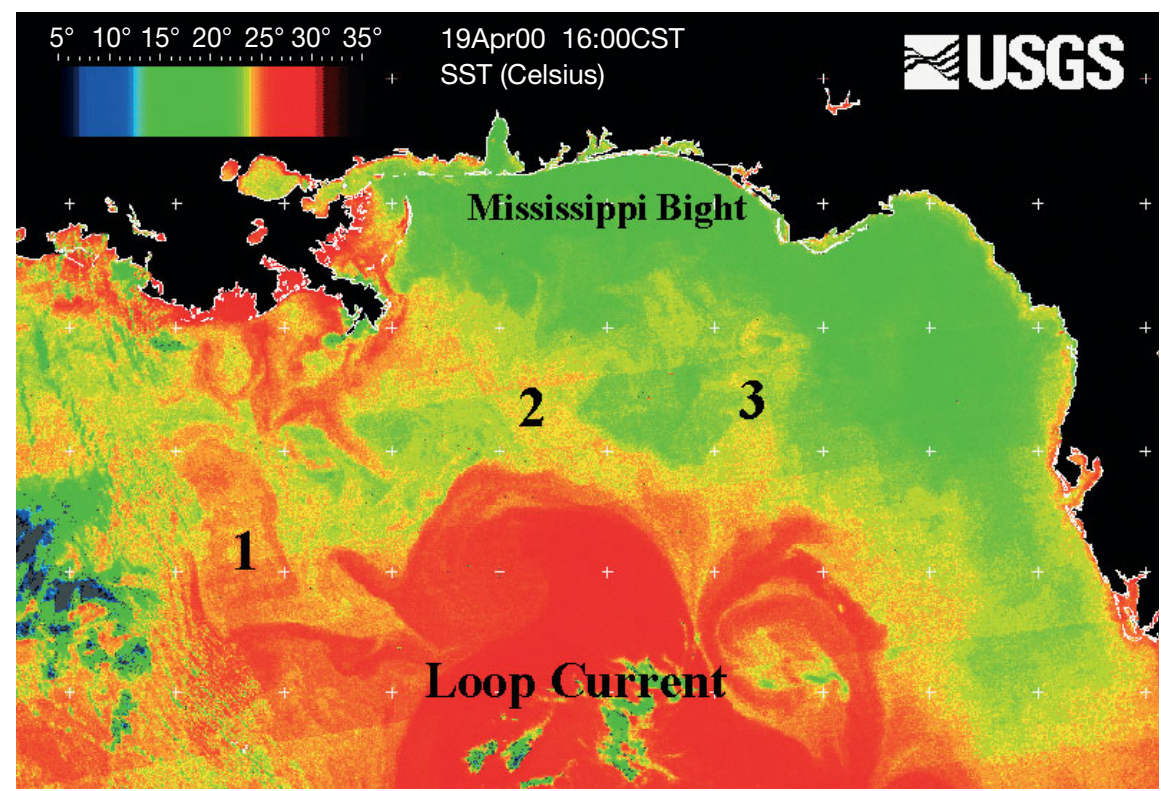

Fig. 2. Mississippi Bight location. Intruding Loop Current (LC) from 19 April 2000, advanced very high resolution radiometry sea surface temperature, SST $\left({ }^{\circ} \mathrm{C}\right)$ composite over 3 d from US Geological Survey (USGS) web site: http://coastal.er.usgs. gov/east_gulf/). 1 to 3: streamers of relatively warm water off LC (see 'Results'). CST: Central Standard Time 
This process was repeated over the time period of interest. The choice of $0.1 \mathrm{~d}$ steps was accepted since endpoint solutions converged down to steps of $0.01 \mathrm{~d}$.

Since the time-line of events indicated that an intrusion might have occurred somewhere around the end of April and beginning of May, we traced backwards from 31 May to 1 April 2000, a 2 mo time scale during which the jellyfish could be expected to develop from ephyra to adult medusa. First, nearshore locations on the shelf around the Mississippi Bight and the Louisiana/Texas shelf were chosen as starting points and point-wise backtracings from these locations were made with the model currents beginning on 31 May. Second, a broad area covering the central and outer shelf in the Mississippi Bight was selected to evaluate the probability of cross-slope flux as a transport mechanism. Third, a study using forward-tracing from Terrebone Bay, Louisiana, was conducted to determine if a more local source were possible (discussed but not illustrated).

Although diffusion was included in the dynamic model, we did not attempt to diffuse patches of jellyfish; rather we treated them as points, with linear interpolation between model grid points and in time. Although
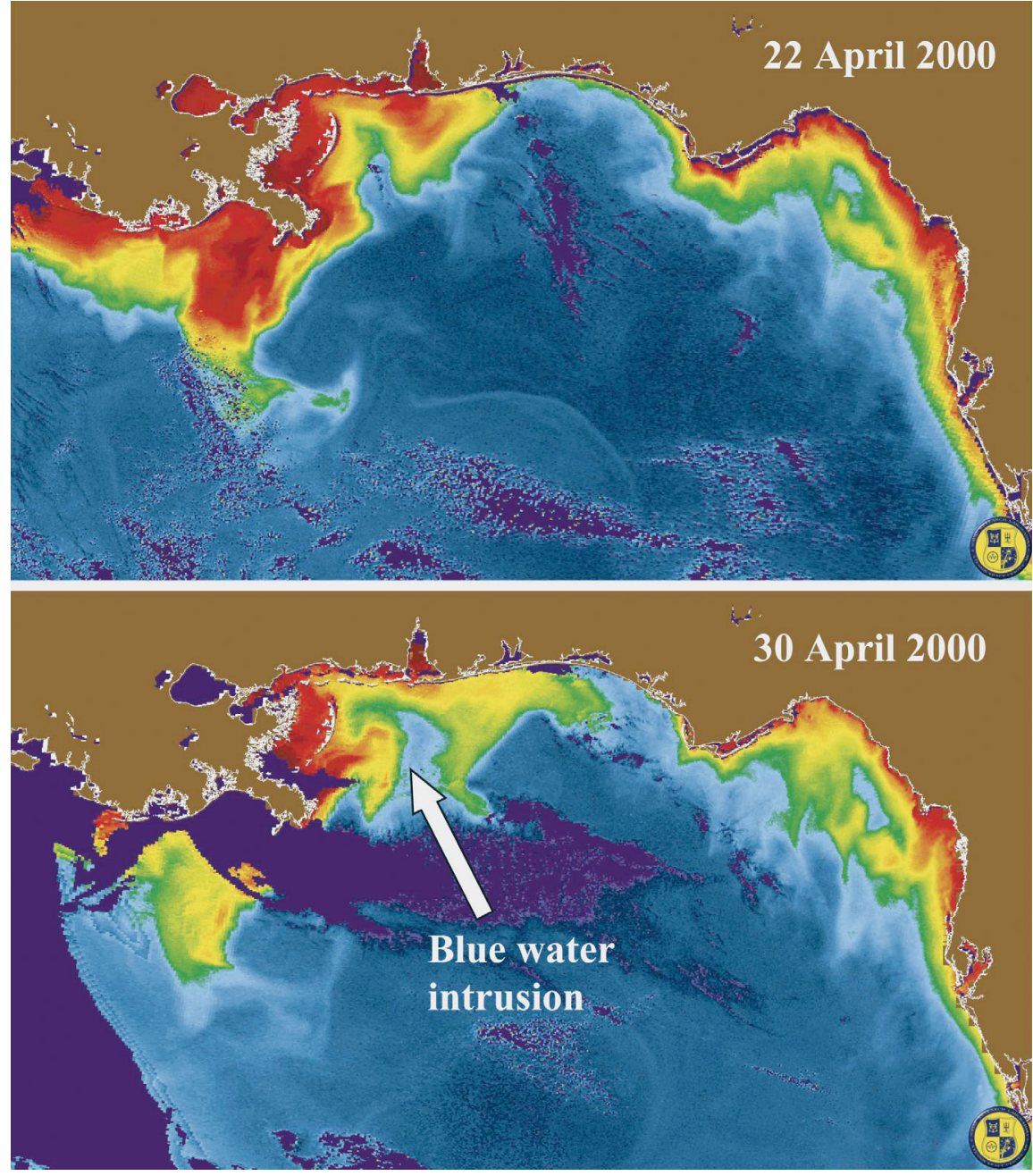

Fig. 3. Chlorophyll a from SeaWifs images of 22 and 30 April 2000, showing intrusion of 'blue' water into western Mississippi Bight

Phyllorhiza punctata swims vertically

very well, it tends to remain in the upper layer of the ocean and relies on near-surface currents for its forward progress. For these reasons we use only the modeled surface currents for tracing advective transport. It should also be noted that surface currents, as part of the frictional boundary layer, are less constrained by vorticity balances across changing bathymetry; hence, basin-shelf exchange is more readily accomplished in surface layers.

\section{RESULTS}

From the anecdotal time-line of the jellyfish invasion, it appeared that an intrusion of deep basin water into the Mississippi Bight occurred in late April 2000. Fig. 3 shows SeaWifs images of chlorophyll a for 22 and 30 April 2000. In the normally high chlorophyll a region of the western Mississippi Bight, there appears to be a distinctive shoreward-pointing tongue of blue, suggesting an intrusion of low chlorophyll a water from offshore. This time frame correlates well with a 19 April AVHRR image showing streamers of relatively warmer water linking the northern shelf with the LC (Fig. 2) and suggests that an intrusive event may have occurred in late April.

The data-assimilative model results for surface current vectors from 20 April are shown in Fig. 4. The plotted vectors show a fairly strong cross-isobath flow $(>25 \mathrm{~cm}$ $\mathrm{s}^{-1}$ ) onto the western Mississippi Bight, which can tentatively be traced back to the LC. This flow is enhanced by smaller anticyclones in the Desoto Canyon and due south of the Mississippi Delta. There are weaker flows onto the Louisiana/Texas and West Florida shelves which do not appear to be directly linked to the LC.

Fig. 5 shows a time series of northward wind stress covering the spring and early summer. These data were taken from an NDBC platform station near the 


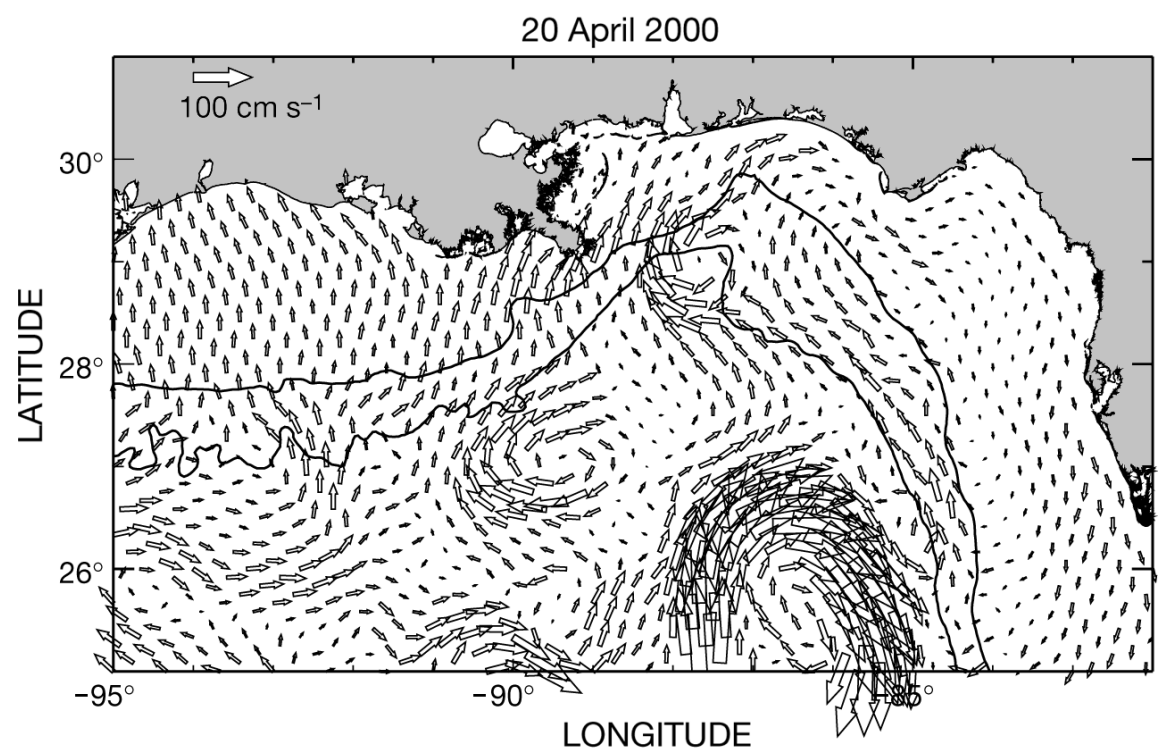

Fig. 4. Surface currents on 20 April 2000 from data-assimilative model; plotting grid was reduced by 8 to show distinct vectors; note pathway from LC onto shelf in the western Mississippi Bight

entrance to the Mississippi River. Fig. 5 shows a period of relatively sustained northward wind stress beginning around 20th of April and continuing through May to late June. This sustained northerly wind stress is consistent with the climatology (Hellerman \& Rosenstein 1983) for the period and is appropriate for the flow onto the shelf near the Mississippi Delta and eastward into the Mississippi Bight (Fig. 4).

There were no systematic mapping efforts (aerial or ship-based) until June 2000 (Graham et al. 2003a), when large quantities of Phyllorhiza punctata were observed in the shallow waters of the western Mississippi Bight. In order to broaden our search for potential crossings onto the shelf, we extended the relevant area from eastern Texas to western Florida and used the modeled current results to work backward from locations in this area. Fig. 6 shows all the starting locations selected for the hindcast effort, together with traces of pathways leading to the LC. Two of the successful pathways began (from a forward-in-time prospective) at the northern head of the LC, crossed the slope near the Mississippi Delta, and ended in the western Mississippi Bight near Mobile Bay. These pathways agree with the intrusion suggested by the SeaWifs chlorophyll a images (Fig. 3), the streamers in the AVHRR composite (Streamer 2 in Fig. 2), and the crossing suggested by the model current vector results from late April (Fig. 4). Another model pathway began in nearly the same location from the northern head of the LC, but took a different route: upon leaving the LC, it went further east, where it apparently became trapped in an along-slope flow up the eastern side of the DeSoto Canyon, exiting near its head and moving onto the West Florida Shelf near Apalachicola. This path correlates well with Streamer 3, in the AVHRR composite (Fig. 2). The remaining successful pathway exited on the western side of the LC and crossed the Louisiana slope west of the Mississippi Delta in accordance with both the 20 April surface current map and the AVHRR composite (Steamer 1 in Fig. 2).

Using the model results, we suggest that jellyfish in the Mississippi Bight bloom entered the Yucatan Strait around 1 to 2 April, left the LC between 6 and 10 April, and crossed the slope region onto the shelf in the northern Gulf around 20 April 2000. This scaling suggests, then, a rapid intrusion into the northern Gulf followed by about $2 \mathrm{wk}$ in deep water before crossing over onto the biologically rich shelf with its advantageous food supply.

To assess the probability of an intrusive event and to explore the robustness of the model, ability to predict such an event, we ran an additional experiment with an array of points covering the shelf of the western Mississippi Bight. We placed 20 points in a rectangular grid, including both shallow and deep water and a back trace run from each of these points (Fig. 7). The results showed that considerable flux of near surface water crossed from the deep basin onto the shelf in the April and May 2000 time period. Most of the flux

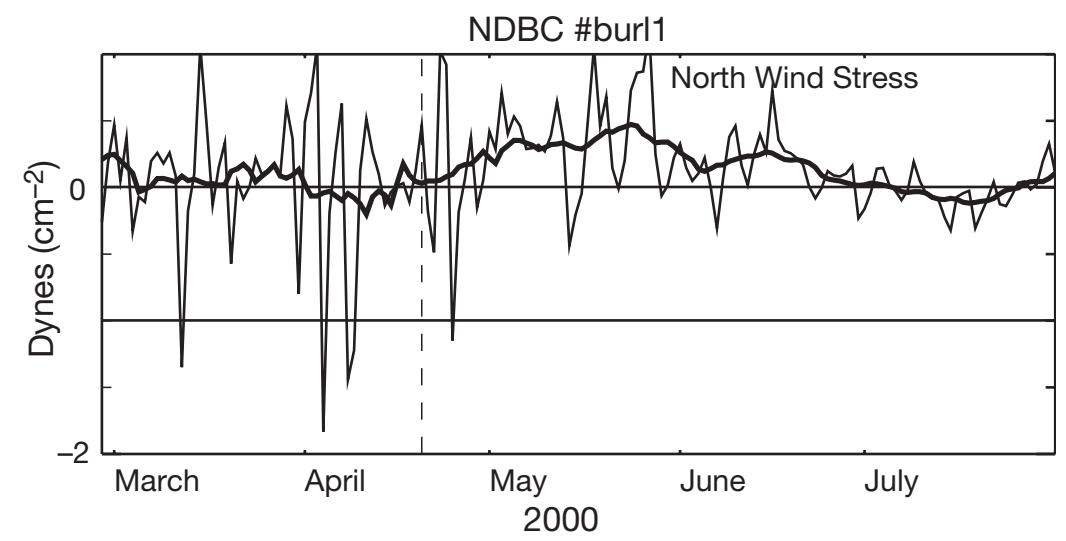

Fig. 5. Daily averaged northward wind stress from NDBC platform \#burl1 located at $89.43^{\circ} \mathrm{W}, 28.90^{\circ} \mathrm{N}$. Boldface curve represents stress smoothed over 14 d intervals; vertical dashed line locates 20 April 2000 


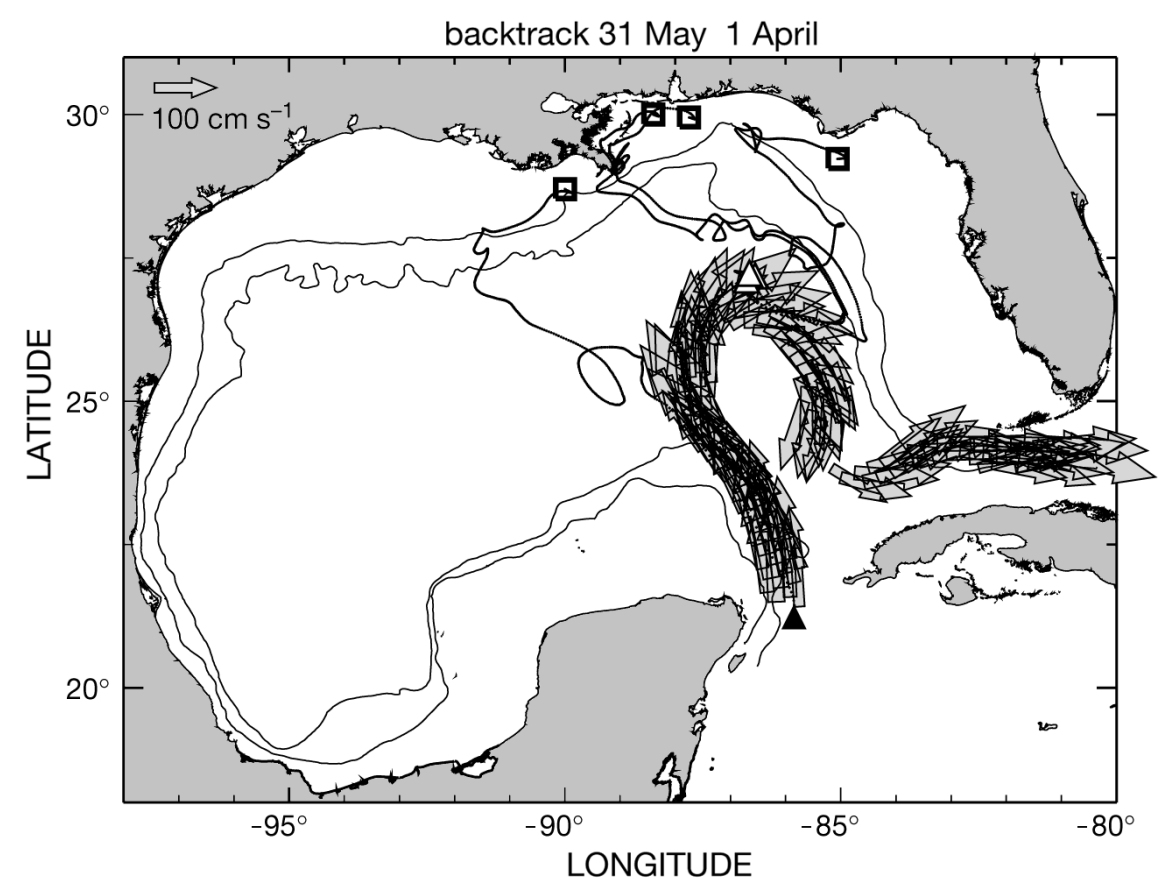

Fig. 6. Back-traced pathways from locations on the shelf starting 31 May (squares) and ending 1 April 2000 (triangles); 200 and $1000 \mathrm{~m}$ isobaths are shown; surface current vectors are from the numerical model for 1 April 2000

crossed in a relatively broad area around the Mississippi River Delta (including the Mississippi Canyon and the western wall of the DeSoto Canyon). The potential origin of this water appears to have been either the LC or a cyclone just north of the LC. In either case the most likely origin of the jellyfish crossing with this water would be from Caribbean water. Of the 20 points, $65 \%$ traced back to the deep basin, $15 \%$ traced to a nearshore origin in the Mississippi Bight, and 20\% traced to the tip of the Mississippi River delta.

Given that the jellyfish first appeared as very large adults and that there was no observation prior to May, we assume that the modeled cluster originating nearshore in the Mississippi Bight was not realistic, and therefore, this is not discussed further. The cluster from the deep basin supports our hypothesis of a Caribbean origin. The eddy just north of the LC may have come from water shed earlier, but the Caribbean hypothesis origin remains the most likely candidate. The cluster of points at the tip of the Mississippi River delta, with extended time, could have originated either in the deep basin or from the Louisiana/ Texas side of the delta.

To more closely examine the potential for crossing over from an origin on the
Louisiana/Texas side, we placed starting points from the entrance to Terrebone Bay $\left(90.63^{\circ} \mathrm{W}, 29.00^{\circ} \mathrm{N}\right)$ to about $56 \mathrm{~km}$ south of the Bay $\left(90.63^{\circ} \mathrm{W}, 28.5^{\circ} \mathrm{N}\right)$. From this array of possible starting points, we traced forward with the model currents from 1 April to 30 May, advancing the starting date by $1 \mathrm{~d}$ at a time. Of the 295 traces, only 1 went eastward into the Mississippi Bight, starting at the most southerly location (furthermost from Terrebone Bay) and grounding quickly on the Chandeleur Islands that line the east side of the Mississippi Delta. Although Terrebone Bay cannot be completely excluded as the source region of Phyllorhiza punctata in the Mississippi Bight, the model results suggest that the Caribbean was the most likely source for the bloom in 2000.

\section{DISCUSSION}

One of the most challenging tasks facing bioinvasion ecologists is the ability to predict the invasiveness of a species. In any particular region, perhaps only $10 \%$ of exotic species introductions result in an established population (Williamson \& Fitter 1996). Although some marine regions appear to be more sensitive to invasions (e.g. oceanic islands, estuaries and other enclosed or semi-enclosed bodies of water), the ability to predict what will invade and when depends on a variety of factors involving recipient and source habitats as well as environmental sto-

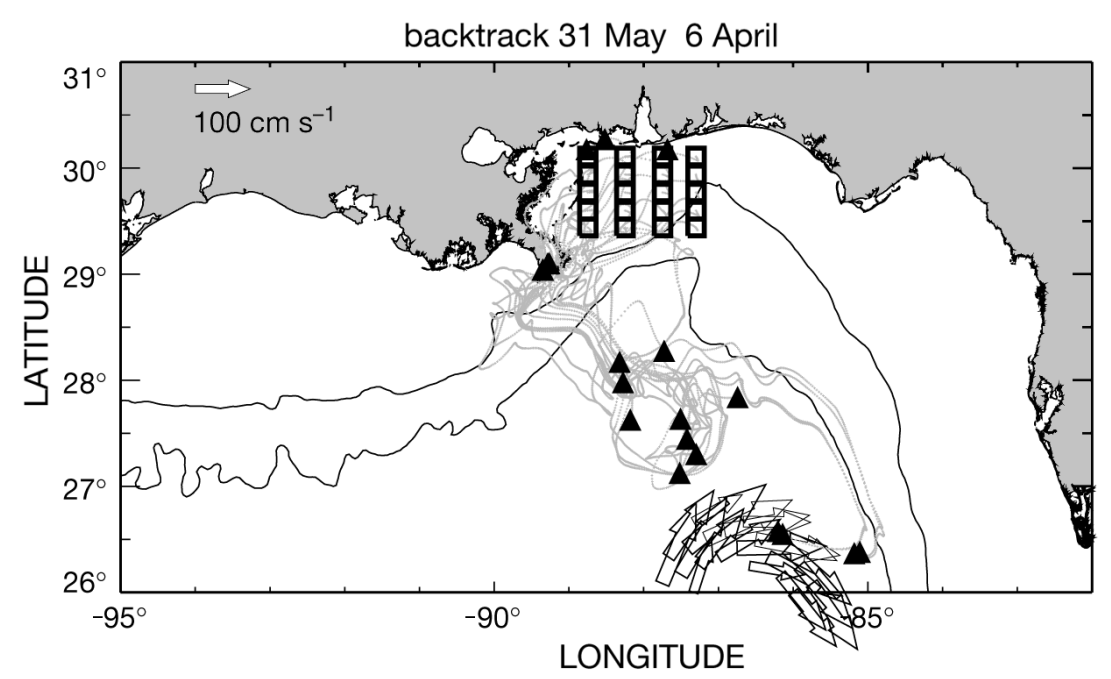

Fig. 7. Back-trace from array of starting points () and end locations ( $(\mathbf{\Lambda})$ in the western Mississippi Bight, 31 May to 6 April 2000. Surface currents in LC are for 6 April 2000 
chasticity (Carlton 1996b). Even when all apparent ecological, physiological and environmental factors appear to be appropriate, invasions do not occur, despite open vector 'corridors' (e.g. shipping routes and ballast discharge). It is particularly interesting that despite its introduction into the Atlantic basin over 45 yr ago (Moreira 1961, Graham et al. 2003a) and the amount of ship traffic between the Caribbean and GOM, Phyllorhiza punctata has only recently emerged in the Mississippi Bight.

Incursions of tropical flora and fauna into the northern Gulf of Mexico are not uncommon, and the literature contains a number of examples indicating the transient occurrence of tropical Caribbean species in northern GOM communities. The LC emerges from the Yucatan Strait carrying a suite of larval fishes (Futch 1977, Zimmerman \& Biggs 1999), zooplankton (Zimmerman \& Biggs 1999, Biggs \& Ressler 2001, Gasca et al. 2001), sea grasses (McMillan \& Phillips 1979) and macroalgae [e.g. Sargassum spp. (Gunn \& Dennis 1973)]. Occasionally, tropical fauna and flora are documented well onto the shelf near the northern Gulf coast (Gunn \& Dennis 1973). The only prior instance of a Caribbean medusa being transported onto the northern Gulf shelf via the Loop Current was the cubomedusa Carybdea alata var. grandis, recovered from a trawl off Mobile Bay, Alabama (Graham 1998). However, establishment of populations from a tropical origin are rare.

To understand how Phyllorhiza punctata might overcome the obstacles of long-distance transport and crossshelf exchange, we considered both the life-history of this jellyfish and the physical mechanism of transport and shelf exchange. Like other Scyphozoa, the medusa stage of $P$. punctata can live for many months (Garcia 1990, Garcia \& Durbin 1993, Graham et al. 2003a). Starvation during transport on the order of $2 \mathrm{mo}$ is not expected to occur, since eddies can be viewed as 'oases' of planktonic productivity, especially along their fringes (Zimmerman \& Biggs 1999, Biggs \& Ressler 2001). Simple point-wise back-tracing with model currents from locations on the shelf from 31 May to 1 April 2000, showed several successful pathways back to the LC. The most direct path indicated that the jellyfish could have passed through the Yucatan Strait on about 1 to 2 April, left the LC between 6 and 10 April, and crossed onto the shelf around 20 April. This timing is appropriate for survival crossing the deep basin and for arrival in the Mississippi Bight in May 2000.

However, even if the LC brought jellyfish into the northern Gulf, there is still the difficulty of crossing the steep continental slope regions onto the shallow shelves. Along-slope currents, density fronts and vorticity balance considerations at the shelf break create a dynamic barrier for cross-isobath flux from the deep basins; yet water is clearly exchanged across the shelf break. The association of Sargassum spp. with the arrival of the jellyfish argues for an oceanic pathway (Graham et al. 2003a). Also, there was a large bloom of Phyllorhiza punctata in southern Louisiana in 2004, and again we noted large amounts of associated sargassum weed. The narrow shelf regions on each side and in front of the Mississippi Delta appear to be locations where shelf break exchanges commonly occur. SeaWifs chlorophyll a images and near real-time model results from 20 to 28 April showed a northern flow and a coincidental tongue of low chlorophyll $a$ water intruding into the western Mississippi Bight at a time appropriate for the invasion.

As an alternative explanation, there is the possibility that the origin of the 2000 Phyllorhiza punctata bloom in the Mississippi Bight was due to advection from a regional source. While a Terrebone Bay-source hypothesis is not as robust as the Caribbean-source hypothesis, it does not preclude the possibility of a common-source location in the northern Gulf that acts as a feeder to both the Mississippi Bight and Terrebone Bay. While flow did uncharacteristically occur from west to east across the Mississippi River Delta during late April 2000, we could not realistically place the source anywhere near Terrebone Bay using model currents.

Although the Caribbean-source/LC advective concept is robust in terms of describing the environmental factors, there were no known direct observations of Phyllorhiza punctata in the LC. We were also late to recognize that a bloom was occurring, so no temperature and salinity measurements of water masses on the continental shelf were taken where the jellyfish were found until late June, when the adults were well into the shallow waters of the Mississippi Sound. Hence, without such direct observations, we can only say that we have shown that such a pathway exists and that the circumstances appear to dictate it as a reasonable solution. In order to get a bloom every year from this path, there would need to be the coincidence of a Caribbean bloom of jellyfish entrained into the Yucatan current, a northward intrusion of the LC, a filament that separates at just the right time and a wind event that carries the filament over the continental shelf break. It seems clear that this scenario will not repeat every year. It should also be expected that local spawning may become successful. With the large number of oil rigs along the Louisiana/Mississippi coast, substrates are certainly available for polyp development.

Carlton (1996b) described a conceptual 'hub and spoke' model, whereby invasion routes open into recipient regions from donor 'hubs' along vector 'spokes'. In this sense, the northern Caribbean Sea, specifically Puerto Rico, was previously invaded by Phyllorhiza punctata (Cutress 1971, Garcia 1990, Garcia \& Durbin 1993), at which time a new transport hub was estab- 
lished. We suggest that the recent occurrence of $P$. punctata in the northern Gulf of Mexico is not a natural range extension, since this species' occurrence could be described more as a 'quantum' jump (from one basin to another) rather than as spread by diffusion (sensu Hastings 1996). Our model back-tracing has shown that such a jump from the Caribbean to the northern Gulf of Mexico could have been mediated by advection in the LC over a biologically reasonable period of time, i.e. 1 to 2 mo.

If the LC is indeed a major pathway, the obvious uncertainty presently before us is whether the northern GOM is now a transport 'hub' or only a way-point along the Caribbean 'spoke'. To answer this question requires information on the source population of Phyllorhiza punctata scyphistomae. Without direct evidence of this benthic stage in the northern GOM, we will need to rely on other sources of biological evidence such as molecular genetic markers. However, until molecular genetic data are available from both GOM and Caribbean populations, we must continue to consider the possibility that the LC serves as a natural invasion route into the northern Gulf.

Acknowledgements. D.R.J. was funded through the Naval Research Laboratory's Accelerated Research Initiative entitled 'Coupled bio-physical dynamics across the littoral transition (COBALT)' under program element $61153 \mathrm{~N}$ sponsored by the Office of Naval Research. H.M.P. was funded by the University of Southern Mississippi, Gulf Coast Research Laboratory. W.M.G was funded by the Mississippi/Alabama Sea Grant Consortium (R/CEH-1 and R/CEH-5) and the National Science Foundation under grant OCE-9733441. We express our appreciation to D. Martin, H. Albright, J. Martin, J. Higgins, T. VanDevender, K. Larsen, and V. Asper for help in our studies.

\section{LITERATURE CITED}

Biggs DC, Ressler PH (2001) Distribution and abundance of phytoplankton, zooplankton, ichthyoplankton, and micronekton in the deepwater Gulf of Mexico. Gulf Mex Sci 19:7-29

Blumberg AG, Mellor GL (1983) Diagnostic and prognostic numerical circulation studies of the South Atlantic Bight. J Geophys Res 88:4579-4592

Carlton JT (1996a) Pattern, process, and prediction in marine invasion ecology. Biol Conserv 78:97-106

Carlton JT (1996b) Biological invasions and cryptogenic species. Ecology 77:1653-1655

Choi JK, Kantha LH (1997) Refinement and verification of a climatological and forecast model of the Loop Current and associated eddies. Colorado Center for Astrodynamics Research, University of Colorado, Report for EJIP - CASE

Cutress CE (1971) Phyllorhiza punctata in the tropical Atlantic. Proc Assoc Island Mar Lab Carib 9:14

Elliot BA (1982) Anticyclonic rings in the Gulf of Mexico. J Phys Oceanogr 12:1292-1309

Futch CR (1977) Larvae of Trichopsetta ventralis (Pisces: Bothidae), with comments on intergeneric relationships within the Bothidae. Bull Mar Sci 27:740-757

Garcia JR (1990) Population dynamics and production of Phyllorhiza punctata (Cnidaria: Scyphozoa) in Laguna Joyuda, Puerto Rico. Mar Ecol Prog Ser 64:243-251

Editorial responsibility: Jennifer Purcell (Contributing Editor), Anacortes, Washington, USA
Garcia JR, Durbin E (1993) Zooplanktivorous predation by large scyphomedusae Phyllorhiza punctata (Cnidaria: Scyphozoa) in Laguna Joyuda. J Exp Mar Biol Ecol 173:71-93

Gasca R, Castellanos I, Biggs DC (2001) Euphausiids (Crustacea, Euphausiacea) and summer mesoscale features in the Gulf of Mexico. Bull Mar Sci 68:397-408

Graham WM (1998) First report of Carybdea alata var. grandis (Reynaud 1830) (Cnidaria: Cubozoa) from the Gulf of Mexico. Gulf Mex Sci 1998:28-30

Graham WM, Martin DL, Felder DL, Asper VL, Perry HM (2003a) Ecological and economic implications of a tropical jellyfish invader in the Gulf of Mexico. Biol Invasions 5:53-69

Graham WM, Martin DL, Martin JC (2003b) In situ quantification and analysis of large jellyfish using a novel video profiler. Mar Ecol Prog Ser 254:129-140

Gunn CR, Dennis JV (1973) Tropical and temperate stranded seeds and fruits from the Gulf of Mexico. Contrib Mar Sci 17:111-121

Hamilton P (1990) Deep currents in the Gulf of Mexico. J Phys Oceanogr 20:1087-1104

Hastings A (1996) Models of spatial spread: Is the theory complete? Ecology 77:1675-1679

Hellerman S, Rosenstein M (1983) Normal monthly wind stress over the world ocean with error estimates. J Phys Oceanogr 13:1093-1104

Hurlbert HE, Thompson JD (1980) A numerical study of Loop Current intrusions and eddy shedding. J Phys Oceanogr 10:1611-1651

Johnson DR, Perry HM (1999) Blue crab larval dispersion and retention in the Mississippi Bight. Bull Mar Sci 65:129-149

Kantha LK, Clayson CA (1994) An improved mixed layer model for geophysical applications. J Geophys Res 99: 25235-25266

Kantha LK, Clayson CA (2000) Data assimilation and nowcasts/forecasts. Academic Press, San Diego, CA

Kantha LK, Piacsek S (1996) Computational ocean modeling. In: Tucker AB Jr (ed) The computer science and engineering handbook. CRC Press, Boca Raton, Fl, p 934-958

Kantha LK, Choi JK, Schaudt KJ, Cooper CK (2006) A regional data-assimilative model for operational use in the Gulf of Mexico. In: New developments in the circulation of the Gulf of Mexico. AGU Monograph (in press)

Lindeman KC, Lee TN, Wilson WD, Claro R, Ault JS (2001) Transport of larvae originating in southwest Cuba and the Dry Tortugas: evidence for partial retention in grunts and snappers. Proc Gulf Caribb Fish Inst 52:732-747

McMillan C, Phillips RC (1979) Differentiation in habitat response among populations of new world seagrasses. Aquat Bot 7:185-196

Moreira MGBS (1961) Sobre Mastigias scintillae sp. nov. (Scyphomedusae, Rhizostomeae) das costas do Brasil. Bol Inst Oceanogr 11:5-30

Perry HM, Johnson DR, Larsen K, Trigg C, Vukovich F (2003) Blue crab larval dispersion and retention in the Mississippi Bight: testing the hypothesis. Bull Mar Sci 72:331-346

Oey LY (1995) Eddy- and wind-forced shelf circulation. J Geophys Res 97:2201-2214

Ruiz GM, Carlton JT, Grosholz ED, Hines AH (1997) Global invasions of marine and estuarine habitats by nonindigenous species: mechanisms, extent, and consequences. Am Zool 37:621-632

Williamson M, Fitter A (1996) The varying success of invaders. Ecology 77:1661-1666

Zimmerman RA, Biggs DC (1999) Patterns of distribution of sound-scattering zooplankton in warm- and cold-core eddies in the northern Gulf of Mexico, from a narrowband acoustic doppler current profiler survey. J Geophys Res 104:5251-5262

Submitted: May 23, 2004; Accepted: December 16, 2004

Proofs received from author(s): December 8, 2005 